\title{
Diagnosis of Liver Involvement in Primary Sjögren Syndrome
}

\author{
Pilar Brito Zeron ${ }^{1}$, Soledad Retamozo ${ }^{1}$, Albert Bové ${ }^{1}$, Belchin Adriyanov Kostov ${ }^{2}$, Antoni Sisó ${ }^{2}$ \\ and Manuel Ramos-Casals ${ }^{1}$
}

\author{
${ }^{1}$ Sjögren Syndrome Research Group (AGAUR), Laboratory of Autoimmune Diseases Josep Font, Institut d'Investigacions \\ Biomèdiques August Pi i Sunyer (IDIBAPS), Department of Autoimmune Diseases, ICMiD, Hospital Clínic, Barcelona, Spain; \\ ${ }^{2}$ Primary Care Research Group, IDIBAPS, Centre d'Assistència_Primària ABS Les Corts, GESCLINIC, Barcelona, Spain
}

\begin{abstract}
Liver involvement was one of the first extraglandular manifestations to be reported in patients with primary Sjögren syndrome (SS). In the 1990s, a study of liver involvement in patients with primary SS integrated the evaluation of clinical signs of liver disease, liver function and a complete panel of autoantibodies. Recent developments in the field of hepatic and viral diseases have significantly changed the diagnostic approach to liver involvement in SS. The most recent studies have shown that, after eliminating hepatotoxic drugs and fatty liver disease, the two main causes of liver disease in primary SS are chronic viral infections and autoimmune liver diseases. The differential diagnosis of liver disease in primary SS (viral vs autoimmune) is clinically important, since the two processes require different therapeutic approaches and have different prognoses. With respect to viral infections, chronic HCV infection is the main cause of liver involvement in SS patients from the Mediterranean area, while chronic HBV infection may be the main cause of liver involvement in SS patients from Asian countries. After eliminating viral hepatitis, primary biliary cirrhosis (PBC) should be considered the main cause of liver disease in primary SS. PBC-related SS patients may have a broad spectrum of abnormalities of the liver, including having no clinical or analytical data suggestive of liver disease. Autoimmune hepatitis (AIH) is the second most frequently found autoimmune liver disease to be associated with SS (all reported cases are type I), and nearly $10 \%$ of these patients have an AIH-PBC overlap. Finally, IgG4-related disease must be investigated in patients with SS presenting with sclerosing
\end{abstract}

Keywords: Sjögren syndrome; Liver disease; Hepatitis B virus; Hepatitis C virus; Primary biliary cirrhosis; Autoimmune hepatitis; Sclerosing cholangitis. Abbreviations: 2-OADC, 2-oxo-acid dehydrogenase complex; $A I H$, autoimmune hepatitis; ANA, anti-nuclear antibodies; ANCA, anti-neutrophil cytoplasmic antibodies; AMA, anti-mitochondrial antibodies; APS, antiphospholipid syndrome; ELISA, enzyme-linked immunosorbent assays; HBV, hepatitis B virus; HCV, hepatitis C virus; HGV, hepatitis G virus; IIF, immunofluorescence; LC-1, liver cytosol type 1; LKM-1, liver kidney microsome type 1; p-ANCA, perinuclear antineutrophil cytoplasmic antibodies; $\mathrm{PBC}$, primary biliary cirrhosis; $\mathrm{PM}$, polymyositis; RA, rheumatoid arthritis; RF, rheumatoid factor; SC, Sclerosing cholangitis; SLA/LPA, soluble liver antigen/liver-pancreas antigen; SLE, systemic lupus erythematosus; SMA, smooth muscle antibodies; SS, Sjögren syndrome; SSc, systemic sclerosis; UCTD, undifferentiated connective tissue disease; UDCA, ursodeoxycholic acid.

Received: 13 September 2013; Revised: 4 October 2013; Accepted: 5 October 2013 DOI of original article: 10.14218/JCTH.2013.00011.

Correspondence to: Manuel Ramos-Casals, Servei de Malalties Autoimmunes, Hospital Clínic, C/Villarroel, 170, Barcelona 08036, Spain. Tel: +34-93-2275774, Fax: +34-93-2271707, E-mail: mramos@clinic.ub.es cholangitis, especially when autoimmune pancreatitis or retroperitoneal fibrosis are also present.

(C) 2013 The Second Affiliated Hospital of Chongqing Medical University. Published by XIA \& HE Publishing Ltd. All rights reserved.

\section{Introduction}

Sjögren syndrome (SS) is a systemic autoimmune disease in which immune-mediated inflammation causes secretory gland dysfunction, leading to dryness of the main mucosal surfaces. ${ }^{1}$ Although xerophthalmia and xerostomia are the most frequent sicca symptoms, nearly $30 \%$ of patients present with extraglandular manifestations, and 5\% may develop a hematological neoplasia. The cause of SS is unknown, but genetic and environmental factors seem to play a role. The disease may be more frequent than was previously thought, affecting an estimated 2-4 million people in the United States, ${ }^{2}$ and with a prevalence of $0.1-3.3 \%$ in European countries. ${ }^{3}$

SS primarily affects white perimenopausal women, with a female:male ratio ranging from $14: 1^{4}$ to $24: 1^{5}$ in the largest reported series. The disease may occur at all ages, but typically has its onset in the fourth to sixth decades of life, although some cases are detected in younger female patients, especially in mothers of babies with congenital heart block. ${ }^{6}$ When sicca symptoms appear in a previously healthy person, the syndrome is classified as primary Sjögren syndrome. When sicca features are found in association with another systemic autoimmune disease, most commonly rheumatoid arthritis (RA), systemic sclerosis (SSc) or systemic lupus erythematosus (SLE), it is classified as associated Sjögren syndrome.

The variability in the presentation of SS may partially explain delays in diagnosis of up to 9 years from the onset of symptoms. ${ }^{1}$ Although most patients present with sicca symptoms, various clinical and analytical features may indicate an undiagnosed SS. In addition, SS is a disease that may be expressed in many guises, depending on the specific epidemiological, clinical or immunological features. Clinically, two main patterns of disease expression are observed: patients with only glandular involvement (sicca-limited disease), who have a low frequency of immunological abnormalities and extraglandular features, and patients with a predominant "systemic" expression in addition to the sicca involvement. ${ }^{1}$ Patients with positive immunological features need a closer follow-up, with special attention to the development of extraglandular manifestations. The therapeutic management of SS is mainly centered on the control of 
sicca features, using substitutive and oral muscarinic agents, while corticosteroids and immunosuppressive agents play a key role in the treatment of extraglandular features.

Gastrointestinal involvement has been little studied in primary SS, and may include altered esophageal motility, gastroesophageal reflux, chronic gastritis and, less frequently, malabsorption. In contrast, liver involvement was one of the first reported extraglandular manifestations included in the systemic expression of SS, and new developments in the field of hepatic and viral diseases have significantly changed the diagnostic approach to patients with SS presenting with altered liver profiles.

\section{Historical overview}

Results of evaluation of liver involvement in primary SS have varied substantially across reported studies owing to the heterogeneity of the definition of hepatic disease. In the first studies published in the 1960s, liver involvement was evaluated exclusively by the presence of hepatomegaly, with a prevalence of $20 \%$. In 1965 , Bloch et $\mathrm{al}^{7}$ found a prevalence of $27 \%$ of liver involvement diagnosed by the presence of hepatomegaly and/or raised alkaline phosphatase in the first well-reported series of patients with SS. In contrast, Golding et $\mathrm{al}^{8}$ reported, in 1970, a close association between SS and liver diseases. The authors found a high frequency of sicca syndrome in patients with various liver diseases, including chronic active hepatitis, primary biliary cirrhosis (PBC) and cryptogenetic cirrhosis. In the 1970s, anti-mitochondrial antibodies(AMA) were included as a marker of liver disease in SS patients. Subsequent studies found a closer association between SS and PBC in comparison with other types of autoimmune liver disease. ${ }^{9,10}$ However, it was not until 1994 when the spectrum of liver diseases in patients with primary SS was fully investigated, including the evaluation of clinical signs of liver disease, liver function tests, and a complete series of autoantibodies. ${ }^{11,12}$

Recent studies have shown that liver function tests may be altered in $10-20 \%$ of patients with primary SS. ${ }^{13}$ After eliminating potentially hepatotoxic drugs, the main causes of liver involvement described in SS are chronic viral infections (especially in geographic areas with a high prevalence) and autoimmune liver diseases. ${ }^{14-16}$ The objective of this article is to comprehensively review the main causes of liver involvement in SS.

\section{Chronic viral hepatitis}

Chronic viral hepatitis has emerged as a significant cause of liver involvement in patients with SS, especially in certain geographical areas, broadening the spectrum of liver diseases classically reported in these patients (Table 1 ). ${ }^{17-19}$ In fact, the geoepidemiology of chronic viral infections is essential in order to evaluate liver involvement in patients with systemic autoimmune diseases.

\section{Hepatitis $C$ virus infection}

The discovery of the hepatitis C virus (HCV) in 1989 radically changed the predominant etiology of liver involvement in SS patients. Further experimental, ${ }^{20,21}$ virological ${ }^{22,23}$ and clinical studies ${ }^{24-26}$ revealed a close association between HCV and SS. In addition, a large multicenter study ${ }^{17}$ showed that $\mathrm{HCV}$-related SS was indistinguishable in most cases from the primary SS form using the main sets of classification criteria. Two thirds of HCV-related SS patients presented with cryoglobulinemia, which may be considered the key immunological marker of SS associated with HCV, and the main cause of vasculitis in these patients. ${ }^{27}$ In primary SS, cryoglobulinemia is associated with extraglandular involvement, an enhanced risk of B-cell lymphoma (Fig. 1), and poor survival, ${ }^{1}$ and in HCV-related SS patients the prevalence of cryoglobulinemia is five-fold higher than those without $\mathrm{HCV}^{27}$

The current classification criteria include chronic HCV infection as an exclusion criterion for the classification of primary SS, not because it mimics primary SS, but because it seems to be directly responsible for the development of SS in a specific subset of HCV patients. ${ }^{17} \mathrm{HCV}$-related SS patients should be considered as a separate subset to those with primary SS. It would be more appropriate to classify these patients as having an HCV-related SS. The term "SS secondary to $\mathrm{HCV}^{\prime \prime}$ might be used in those cases in which infection of salivary gland epithelium by $\mathrm{HCV}$ is directly demonstrated.

Some recent studies have investigated etiopathogenic factors involved in HCV-related SS. Genetic factors may play a role in the development of HCV-related SS. Smyth et $\mathrm{al}^{28}$ have reported that HCV patients carrying the HLA DQB1*02 allele had a higher frequency of sicca syndrome. In addition, human La protein has been recently implicated in facilitating the internal initiation of translation as well as replication of HCV RNA. ${ }^{29}$ It could be hypothesized that patients carrying anti-La antibodies may be protected against chronic HCV infection. We analyzed the possible association between antiLa antibodies and chronic HCV infection in a large series of patients with SS, and found that the main differential aspect between primary and HCV-related SS was the immunological pattern, with a predominance of cryoglobulinemia-related markers [mixed cryoglobulins, rheumatoid factor (RF), hypocomplementemia, monoclonal band] over SS-related specific markers (anti-Ro/SS-A and anti-La/SS-B autoantibodies) in $\mathrm{HCV}$-related SS. We confirmed that cryoglobulinemia was the key immunological marker of SS associated with HCV, while anti-La antibodies were less frequently detected in HCV patients, and do not seem to protect against chronic HCV infection in SS patients. ${ }^{30}$

In Mediterranean countries, chronic HCV infection is the main cause of liver involvement in patients with SS, with a prevalence of $13 \%$ - nearly three-fold greater than that observed for autoimmune liver involvement. ${ }^{16} \mathrm{~A}$ recent study by Nawito et $\mathrm{al}^{31}$ found a prevalence of sicca syndrome of $55 \%$ in 120 Egyptian patients with chronic HCV infection. This underlies the importance of chronic HCV infection as a cause of liver disease in SS patients from specific geographical regions that have high prevalences of $\mathrm{HCV}$ infection in the general population.

\section{Hepatitis B virus infection}

Chronic hepatitis B virus (HBV) infection is associated with various extrahepatic manifestations, including skin rash, arthritis and glomerular disease. ${ }^{32}$ In addition, a close association between HBV and polyarteritis nodosa was reported by Guillevin et al in 1981,33 while other studies have suggested a possible association between HBV and other systemic autoimmune diseases, such as RA, rheumatic polymyalgia, antiphospholipid syndrome (APS) and SLE. ${ }^{34}$ However, there are no data suggestive of a causal role of HBV 
Ramos-Casals M. et al: Liver disease in primary Sjögren syndrome

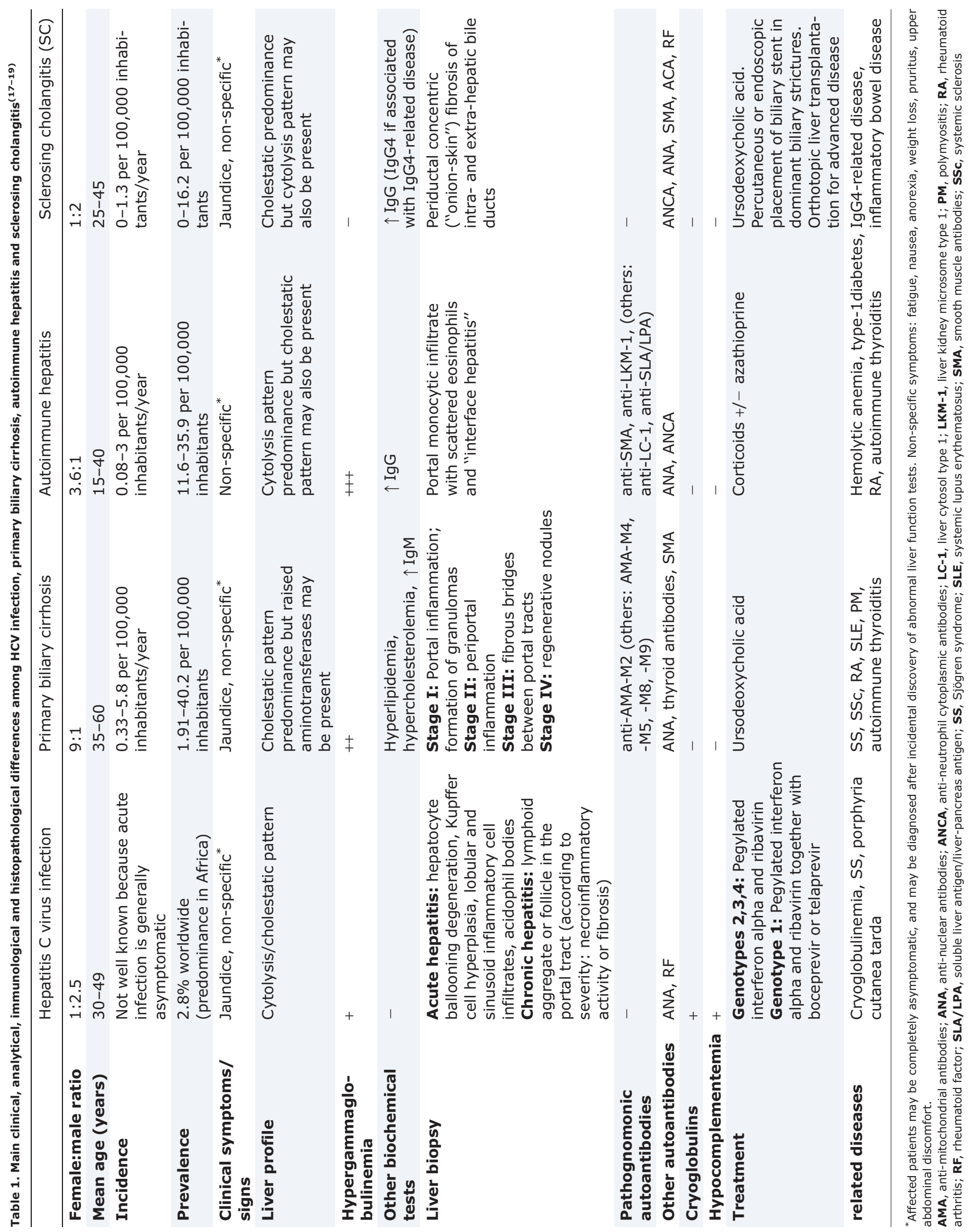




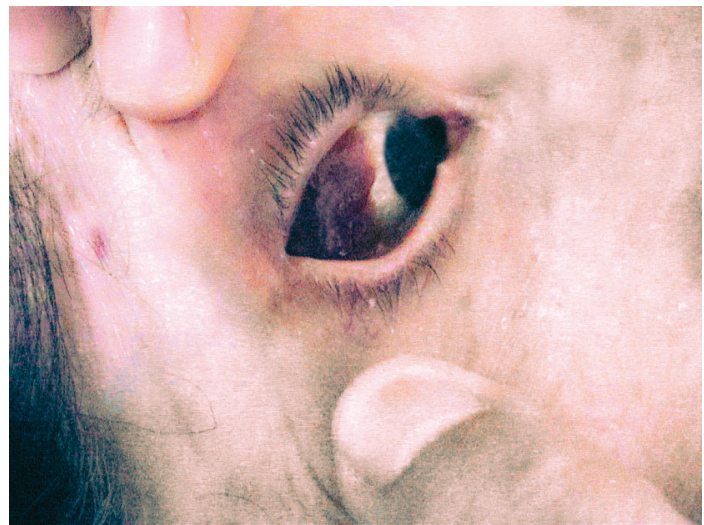

Fig. 1. Ocular B-cell lymphoma in a patient with chronic hepatitis C virus and Sjögren syndrome

in these diseases, ${ }^{35}$ and one study has even suggested a lower frequency of HBV infection in patients with autoimmune diseases. ${ }^{36}$ It has also been suggested that previous exposure to HBV might protect against the development of autoimmune diseases due to mechanisms such as antigen competition or down-regulation of allergic and autoimmune responses. ${ }^{36-38}$ Although the reasons for the specific predilection of HCV for exocrine tissue are unknown, differences either in the viral structure (HBV is a DNA virus, while HCV is an RNA virus) or in the autoimmune responses they trigger might explain the variation in sialotropism.

The association between SS and HBV depends on the geographical area in which the association is investigated. In European studies, this association is very infrequent. Only one case of chronic HBV infection was found in 475 Spanish SS patients, in comparison with 63 patients with chronic HCV infection. ${ }^{39}$ Three additional cases ${ }^{40-42}$ of HBV-related SS have been reported (one associated with HBV vaccination). In a recent study, ${ }^{43}$ we found a prevalence of chronic HBV infection of $0.83 \%$ in SS, a very similar prevalence to that found in the general population in Spain $(0.7 \%) .{ }^{44}$ In spite of the few reported cases of HBV-related SS, a comparison between primary SS and HBV-related SS reveals some differences. The clinical expression of HBV-related SS is similar to that of primary SS with respect to the prevalence of sicca features, except for a higher percentage of patients with joint involvement. With respect to immunological expression, HBV-related SS patients had a higher frequency of $\mathrm{RF}$, but a lower frequency of some immunological features typically described in HCV-related SS patients, such as hypocomplementemia and cryoglobulinemia. In contrast to the close association between SS and HCV, chronic HBV infection is not associated with SS in our geographical area (Barcelona, Spain), with a ratio of HBV-related SS:HCVrelated SS cases of $1: 10$.

However, recent studies have suggested a different role of $\mathrm{HBV}$ in SS patients from Asian countries. Chen et $\mathrm{al}^{45}$ have recently reported a $10 \%$ prevalence of $\mathrm{HBV}$ infection in patients with primary SS from Taiwan. Approximately three million people in Taiwan are infected with HBV, and a largescale survey found a prevalence rate of HBsAg (hepatitis B surface antigen)-positive patients of $17 \% .{ }^{46}$ Although the prevalence of HBV infection in Taiwanese patients with SS was 10-fold higher than that found in European SS patients, the prevalence was lower than that found in the general population of Taiwan ( $10 \%$ vs $17 \%, \mathrm{p}<0.001)$. In contrast, Kang et $\mathrm{al}^{47}$ have reported that Taiwanese patients with SS had a 2.3-fold higher risk of having associated HBV infection in comparison with the general Taiwanese population. The differing results obtained by these two studies suggest that further research is needed to evaluate whether the prevalence of HBV infection in Asian patients with primary SS is higher or lower with respect to the prevalence of HBV infection found in the general population of the same geographical area.

\section{Other chronic hepatitis viral infections}

No cases of association between other hepatitis viral infections (hepatitis A, D, E) and SS have been reported. In 1998, we reviewed the prevalence and clinical significance of hepatitis G virus (HGV) infection in 100 Spanish patients with primary SS. Four patients (4\%) and six volunteer blood donors $(3 \%)$ were found to have HGV-RNA sequences in serum. HGV infection was associated with biochemical signs of liver involvement in only two $(50 \%)$ of the patients with primary SS. When compared with patients without HGV infection, no significant differences were found in terms of clinical or immunological features. HCV co-infection occurred in one $(25 \%)$ of the four SS patients with HGV infection. We concluded that HGV infection alone was not a significant cause of chronic liver involvement in patients with primary SS. ${ }^{48}$

\section{Organ-specific autoimmune liver diseases}

\section{Primary biliary cirrhosis}

Primary biliary cirrhosis (PBC) is an organ-specific autoimmune liver disease, characterized by the chronic progressive loss of interlobular bile ducts, that primarily affects middleaged women of all races. An immune-mediated destruction of the bile duct epithelium is thought to mediate its pathogenesis, histologically characterized by portal inflammation comprising aggregates of lymphoid cells and/or granulomas, which invade and destroy biliary epithelial cells. ${ }^{49}$ Although there are no standardized diagnostic criteria, the majority of studies consider a diagnosis of PBC in the presence of at least two of the following features: (1) biochemical data of cholestatic liver disease, (2) positive AMAs, and (3) histological features of PBC in liver biopsy (Table 1).

\section{Prevalence of AMA in SS}

Serologically, the diagnostic hallmark of PBC is the presence of significant titers of AMA, which is possibly the most specific autoantibody in clinical immunology. Elevated AMA is detected in nearly $100 \%$ of PBC patients when diagnostic tests based on recombinant antigens are used. ${ }^{49}$ AMA is directed against the 2-oxo-acid dehydrogenase complex (2OADC), ${ }^{36}$ most frequently against the E2- and E3-binding protein components of the pyruvate dehydrogenase complex, and against the E2 components of the 2-oxo- glutarate dehydrogenase and branched-chain 2-oxo-acid dehydrogenase complexes. ${ }^{49}$

Several studies have analyzed the prevalence of AMA in patients with primary SS using the currently available methods for its detection: indirect immunofluorescence (IIF), enzyme-linked immunosorbent assays (ELISA) or 
Ramos-Casals M. et al: Liver disease in primary Sjögren syndrome

Western blot tests. Studies using IIF found a prevalence ranging from $1.6 \%$ to $13 \%, 11,12,16,50$ while studies using ELISA/Western blot found higher prevalences (22$27 \%) .{ }^{12,51-53}$ The discrepancy in prevalences may be explained by the low sensitivity of IIF. Although IIF is widely used for its technical simplicity and cost effectiveness, it lacks sensitivity, and in up to $10 \%$ of patients diagnosed with PBC, AMA cannot be detected by this technique. ${ }^{54}$ Therefore, in patients who are strongly suspected of having PBC, but test negative for AMA with IIF, more sensitive techniques are recommended, such as ELISA. However, there are patients who test negative for AMA by any of the methods described above despite clinical and biochemical findings supporting the diagnosis of PBC. In such cases, a diagnosis of PBC should be confirmed by liver biopsy.

Prevalence of PBC in SS

The prevalence of $\mathrm{PBC}$ in patients with primary SS ranges from $4 \%$ to $9 \%$ according to the five studies found in the literature (Table 2), ${ }^{11,16,53,55,56}$ with two studies including more than 400 primary SS patients. ${ }^{16,53}$

Prevalence of SS in PBC

Three studies have analyzed the prevalence of systemic autoimmune diseases in PBC (Table 3). ${ }^{57-59}$ Two of these studies found SS to be the most prevalent systemic autoimmune disease in patients with PBC. ${ }^{58,59}$ Wang et al ${ }^{59}$ found that $36 \%$ of 322 patients with PBC had SS, followed by SLE with a prevalence of $4 \%$. Gershwin et $\mathrm{al}^{58}$ found a lower prevalence of SS (10\%) in 1032 patients with PBC. The same prevalence $(10 \%)$ was found for RA. Finally, an Italian study including 170 PBC patients ${ }^{57}$ found that SSc was the most frequently associated systemic autoimmune disease (12\%), followed by SS (3.5\%).

\section{Clinical expression of PBC in SS}

PBC and SS share several clinical, histological and serological features. According to several studies, characteristic symptoms of SS such as dry mouth or dry eyes are also commonly found $(47-73 \%)$ in PBC. In addition, objective findings of dry eyes or dry mouth (such as abnormal Schirmer test, or diminished salivary flow rate) are also found in $30-50 \%$ of patients with PBC. ${ }^{60,61}$ Furthermore, PBC patients frequently (26-93\%) manifest histological changes in salivary gland biopsies that are compatible with a diagnosis of SS, ${ }^{10,62,63}$ especially at early disease stages of PBC when a CD4+ lymphocyte infiltration predominates. ${ }^{61}$

Regarding immunological profiles, serum anti-nuclear antibodies (ANA) are frequently observed in both conditions, but with a higher prevalence in SS compared with PBC. Also, patients with SS have significantly higher frequencies of antiRo and anti-La autoantibodies, while patients with PBC have significantly higher frequencies of autoantibodies to AMA Sm, Jo-1, collagen and MPO. ${ }^{64}$ The frequencies of HLA-B8, -DR3 and -DRW52 are also lower in PBC patients compared with those in primary SS patients.

We found a broad spectrum of abnormalities in the liver laboratory profile of SS patients with AMA-M2, including three patients with no clinical or analytical data suggestive of liver disease, ${ }^{16}$ as has been reported in five previous cases. ${ }^{11-13}$ Previous studies in non-SS patients have shown that AMA-M2 patients with any clinical or analytical signs of liver involvement have a high risk of developing symptomatic PBC, ${ }^{65}$ underlining the key role of AMA-M2 as an early immunological marker of $\mathrm{PBC}^{15}$ and suggesting the existence of an incipient or incomplete PBC in some patients with primary SS. ${ }^{16}$ Hatzis et $\mathrm{al}^{53}$ found a diverse clinical scenario: the majority of AMApositive patients had acholestatic liver biochemistry, and were diagnosed as having definite $(n=10)$ or probable $(n=11)$ $\mathrm{PBC}$ according to the histological confirmation, while six

Table 2. Studies on the prevalence of PBC and AIH in primary SS patients

\begin{tabular}{|c|c|c|c|c|}
\hline Author (year) & Country & Primary SS (n) & PBC n (\%) & $\mathrm{AIH} n(\%)$ \\
\hline Lindgren et al (1994) & Sweden & 45 & $4(9)$ & $2(4)$ \\
\hline Ramos-Casals et al (2006) & Spain & 475 & $16(4)$ & $8(2)$ \\
\hline Montaño-Loza et al (2007) & Mexico & 95 & $5(5)$ & $2(2)$ \\
\hline Hatzis et al (2008) & Greece & 410 & $27(6.6)^{\dagger}$ & NA \\
\hline Karp et al (2010) 56 & USA & $194^{+}$ & NA & $2(1)$ \\
\hline
\end{tabular}

AIH, autoimmune hepatitis; NA, not available; PBC, primary biliary cirrhosis; SS, Sjögren syndrome Including patients with either definite, probable or AMA-negative PBC

*atients with Sjögren syndrome and/or sicca symptoms

Table 3. Studies on the prevalence of systemic autoimmune diseases in PBC patients

\begin{tabular}{|c|c|c|c|c|c|c|c|c|}
\hline Author (year) & Country & $\operatorname{PBC}(n)$ & SS n (\%) & RA n (\%) & SLE n (\%) & SSc n (\%) & PM n (\%) & UCTD n (\%) \\
\hline Marasini et al (2001) & Italy & 170 & $6(3.5 \%)$ & $3(2)$ & $3(2)$ & $21(12)$ & $1(1)$ & $12(7)$ \\
\hline Gershwin et al (2005) & USA & 1032 & $102(10)$ & $103(10)$ & $27(3)$ & $24(2)$ & $6(0.6)$ & - \\
\hline Wang et al (2013) & China & 322 & $121(36)$ & $9(2.8)$ & $12(4 \%)$ & $9(3)$ & $10(3)$ & - \\
\hline TOTAL & & 1524 & $229(15)$ & $112(7.5)$ & $42(3)$ & $53(3.5)$ & $17(1)$ & $12(0.8)$ \\
\hline
\end{tabular}

PBC, primary biliary cirrhosis; PM, polymyositis; RA, rheumatoid arthritis; SLE, systemic lupus erythematosus; SS, Sjögren syndrome; SSc, systemic sclerosis; UCTD, undifferentiated connective tissue disease 
additional patients had a biopsy-proven PBC, but negative AMA, and were diagnosed as having AMA-negative PBC.

The high prevalence of PBC in primary SS and vice versa may suggest that both diseases share common etiopathogenic mechanisms. In both conditions, environmental triggers (putatively infectious agents and xenobiotics) may cause salivary or biliary epithelial cell apoptosis, and may contribute to tolerance breakdown to self-antigens exposed on the apoptotic blebs (SSA and SSB) and not protected by post-translational modification (PDC-E2). Salivary and biliary epithelial cells contribute to the autoimmune process by expressing cytokines, HLA class II antigens and adhesion molecules. ${ }^{61,66,67}$

\section{Outcome and management of PBC-associated SS}

Few studies have evaluated the outcome of PBC in patients with primary SS. ${ }^{16,53}$ Hatzis et $\mathrm{al}^{53}$ reported that PBC in primary SS appears to progress slowly. The authors evaluated clinical, biochemical and histological data during a mean follow-up of 66 months after diagnosis of PBC, and found that only 1 patient with probable PBC showed clinical deterioration, while 8 patients ( 3 with definite PBC, 4 with probable $\mathrm{PBC}$, and 1 with $\mathrm{AMA}$-negative $\mathrm{PBC}$ ) showed biochemical deterioration. A second liver biopsy was carried out in five patients, and no progression was found between the first and the second biopsies after a mean follow-up of nearly 46 months.

After eliminating viral hepatitis, PBC should be considered as the main cause of liver disease in patients with primary SS. Although historically these patients have been considered as having a "secondary" SS, it seems more rational to use the term "PBC-associated SS", owing to the clinical-based evidence that SS is associated with (and not secondary to) other autoimmune diseases. The inclusion of AMA in the routine immunological follow-up of SS patients should be recommended, independently of whether the serum liver profile is altered or not, because of the strong association between AMA and the development of PBC, and because a significant percentage of patients with primary SS may have an asymptomatic underlying PBC. Although there are no therapeutic guidelines for such asymptomatic patients, early use of ursodeoxycholic acid (UDCA) may be considered, since some studies on non-SS patients with mild serum test abnormalities have suggested that treatment with UDCA might prevent a possible evolution to liver cirrhosis. ${ }^{68}$

\section{Autoimmune hepatitis}

Autoimmune hepatitis (AIH) is a chronic autoimmune liver disease characterized histologically by interface hepatitis, biochemically by elevated transaminase levels, and serologically by the presence of autoantibodies and hypergammaglobulinemia $^{49}$ (Table 1 ). Anti-smooth muscle and/or antinuclear antibodies defines type-1 $\mathrm{AIH}$, while positivity for liver kidney microsomal type-1 antibodies defines type-2 $\mathrm{AIH}$, which is more common in children. ${ }^{49}$

\section{Type-1 AIH in SS}

Type-1 AIH is the second most frequently found autoimmune liver disease associated with SS. The frequency of AIH in primary SS ranges from $1 \%$ to $4 \%$ according to four studies (Table 2). ${ }^{11,16,55,56}$ Up to 2009,56 cases of type-1 AIH had been reported in patients with primary SS. ${ }^{60} \mathrm{~A}$ specific characteristic of AIH associated with primary SS is that twothirds of cases have been reported from Asian countries. In addition, nearly $10 \%$ of AIH patients had positive AMA (AIH$\mathrm{PBC}$ overlap). These patients may have histological features compatible with both $\mathrm{AIH}$ and $\mathrm{PBC}$, and have a cholestatic biochemical pattern. ${ }^{60} \mathrm{~A}$ recent study showed that SS was the systemic autoimmune disease most frequently reported to be associated with AIH-PBC overlap syndrome ( 6 out of 71 patients, $8 \%)$. $^{69}$

A recent study ${ }^{55}$ evaluated the prognostic implications of antibodies to Ro/SSA in patients with type- $1 \mathrm{AIH}$, and reported that anti-Ro52 antibodies (alone or in combination with antibodies to soluble liver antigen) were independently associated with a poor prognosis.

\section{Type-2 AIH in SS}

There are no reported cases of type-2 AIH in patients with primary SS, a fact that is consistent with the lack of positive anti-LKM-1 antibodies in SS. The prevalence of anti-LKM-1 antibodies has been evaluated in a large series of patients with primary SS, and none of the 335 patients tested had these autoantibodies. ${ }^{50}$

\section{Sclerosing cholangitis}

Sclerosing cholangitis (SC) is a chronic cholestatic liver disease characterized by the presence of intrahepatic and/ or extrahepatic biliary duct concentric and obliterative fibrosis. ${ }^{49}$ This organ-specific autoimmune hepatobiliary disease is frequently associated with positive autoantibodies including ANAs, anti-cardiolipin antibodies and perinuclear anti-neutrophil cytoplasmic antibodies ( $\mathrm{p}$-ANCA) (Table 1).

Thirteen cases of SC have been described in patients with primary SS. ${ }^{16}$ Certain characteristics of patients with SS and associated SC should be highlighted: a specific pattern of clinical features at presentation of SC (abdominal pain, jaundice and diarrhea), an overwhelming association with chronic pancreatitis in all but one case (with pancreatic masses demonstrated by CT abdominal scan), and an association with other autoimmune processes such as retroperitoneal fibrosis. These specific features may help to reach an early diagnosis of this rare disease in patients with primary SS. However, investigation of a possible IgG4-related disease should be mandatory in all patients with SS diagnosed with $\mathrm{SC}$, especially when autoimmune pancreatitis or retroperitoneal fibrosis is also present.

\section{Other autoimmune liver diseases}

Other autoimmune liver diseases in patients with primary SS have been described rarely, including seven cases of autoimmune cholangitis, one case of nodular regenerative hyperplasia of the liver $^{16}$ and one case of granulomatous hepatitis. $^{70}$

\section{Conclusions}

The most recent studies have shown that the two main causes of liver disease in patients with primary SS are associated processes such as chronic viral infections and autoimmune liver diseases (Table 4). 
Detection of an altered liver profile in a patient with SS requires a sequential diagnosis (Fig. 2):

- The first step is to eliminate processes not associated with SS, mainly the chronic use of potential hepatotoxic drugs, fatty liver and congestive heart failure.

- The second step is to evaluate epidemiological features. With respect to viral infections, HCV infection will be more frequently found in SS patients from the Mediterranean area, while HBV infection should be principally investigated in Asian patients. With respect to gender and age, the diagnosis of HCV will be more frequent in older and male SS patients, while younger and female SS patients will be more likely to have an associated autoimmune liver disease.

- The third step is the evaluation of liver tests: raised aminotransferases suggest viral or autoimmune hepatitis, while a cholestatic pattern suggests PBC or SC. Liver profiles are not useful in differentiating between viral- and autoimmune-related liver diseases in all cases.

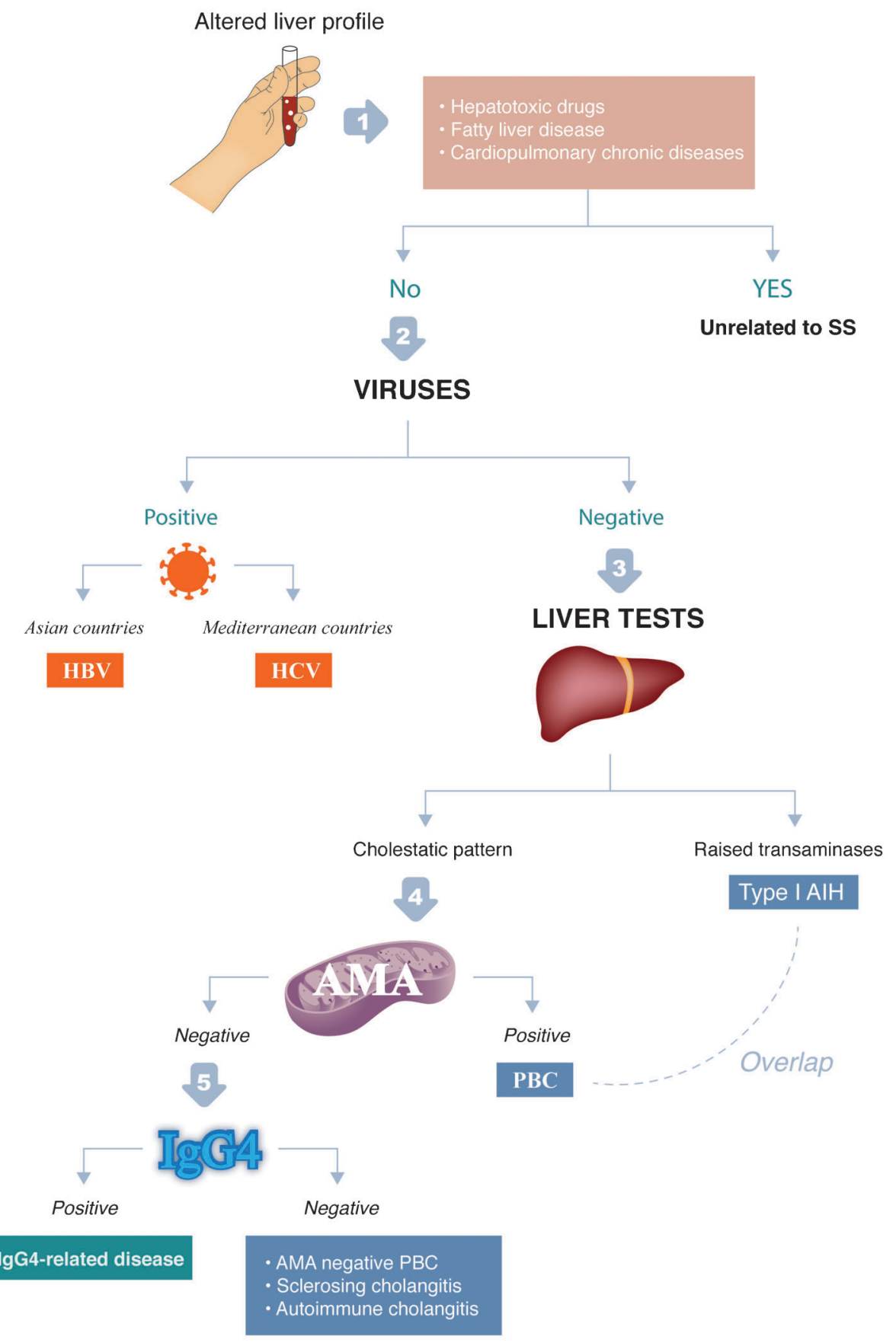

Fig. 2. Sequential diagnosis for patients with Sjögren syndrome presenting with altered liver profile 
Ramos-Casals M. et al: Liver disease in primary Sjögren syndrome

Table 4. Diagnosis of liver involvement in Sjögren syndrome: Clinical pearls

- The differential diagnosis of liver disease in patients with primary SS (viral versus autoimmune) is clinically important, since the two processes have different therapeutic approaches and prognoses.

- In Mediterranean countries, chronic HCV infection is the main cause of liver involvement in patients with SS, with a prevalence nearly three-fold greater than that observed for autoimmune liver involvement.

- In SS patients from Asian countries, chronic HBV infection may be the main cause of liver involvement.

- After eliminating viral hepatitis, PBC should be considered as the main cause of liver disease in patients with primary SS.

- Patients with SS-related PBC may have a broad spectrum of abnormalities, including no clinical or analytical data suggestive of liver disease.

- In patients with primary SS, PBC appears to progress slowly.

- Early use of ursodeoxycholic acid may be considered in patients with PBC associated with SS.

- Autoimmune hepatitis is the second most frequently found autoimmune liver disease associated with SS (all reported cases are type-I AIH).

- Two-thirds of cases of type-I AIH associated with primary SS are reported from Asian countries.

- Nearly $10 \%$ of SS-related type-I AIH patients may have positive AMA (AIH-PBC overlap).

- There are no reported cases of type-2 AIH in patients with primary SS, a disease in which no anti-LKM-1 antibodies are detected.

- IgG4-related disease must be investigated in patients with SS presenting with sclerosing/autoimmune cholangitis, especially when autoimmune pancreatitis or retroperitoneal fibrosis are also present.

- The fourth step is the evaluation of the immunological profile, which plays a key role in differentiating between the main etiologies: patients with chronic HCV infection will have a higher frequency of cryoglobulins and hypocomplementemia, while those with autoimmune liver disease will have, predominantly, hypergammaglobulinemia and positive autoantibodies (AMA, ANA, SMA, Ro and La). In SS patients with a suspected autoimmune liver disease, the existence of AMA with a specific M2 pattern clearly indicates PBC, while high titers of ANA and antiSMA suggest type-1 AIH.

- The fifth step is to eliminate IgG4-related disease in SS patients presenting with autoimmune or SC, especially in cases with associated autoimmune pancreatitis, retroperitoneal fibrosis or inflammatory bowel disease, or presenting with atypical autoantibodies such as antiphospholipid antibodies or p-ANCA.

\section{Conflict of interest}

None

\section{Author contributions}

writting the manuscript (PBZ, MRC), creating tables (SR), searching the literatures and creating figure $2(A B, B A)$, doing the reference list and formatting the article (AS).

\section{Acknowledgments}

Supported by Grants La Marató de TV3 (071810), Fondo de Investigaciones Sanitarias (080103/1201009), and "Ajut per a la Recerca Josep Font" from Hospital Clinic-Barcelona (PBZ, 2012)

\section{References}

[1] Ramos-Casals M, Brito-Zerón P, Sisó-Almirall A, Bosch X. Primary Sjögren syndrome. Br Med J 2012;344:e3821.

[2] Helmick CG, Felson DT, Lawrence RC, Gabriel S, Hirsch R, Kwoh CK, et al. National Arthritis Data Workgroup. Estimates of the prevalence of arthritis and other rheumatic conditions in the United States. Part I. Arthritis Rheum 2008;58:15-25.

[3] Ramos-Casals M, Font J. Primary Sjögren's syndrome. In: Current Diagnosis and Treatment in Rheumatology, ed. EdsImboden J, Hellmann D, Stone J. McGraw-Hill, USA, 2007; pp 237-245.

[4] García-Carrasco M, Ramos-Casals M, Rosas J, Pallares L, Calvo-Alén J, Cervera $\mathrm{R}$, et al. Primary Sjögren syndrome: clinical and immunologic disease patterns in a cohort of 400 patients. Medicine 2002;81:270-280.

[5] Skopouli FN, Dafni U, Ioannidis JP, Moutsopoulos HM. Clinical evolution, and morbidity and mortality of primary Sjögren's syndrome. Semin Arthritis Rheum 2000;29:296-304.

[6] Haga HJ, Gjesdal CG, Koksvik HS, Skomsvoll JF, Irgens LM, Ostensen M. Pregnancy outcome in patients with primary Sjögren's syndrome. A casecontrol study. J Rheumatol 2005;32:1734-1736.

[7] Bloch KJ, Buchanan WW, Wohl M], Bunim JJ. Sjögren's syndrome. A clinical, pathological, and serological study of sixty-two cases. Medicine 1965;44: 187-231.

[8] Golding PL, Bown R, Mason AM, Taylor E. "Sicca complex" in liver disease. $\mathrm{Br}$ Med J 1970;4:340-342

[9] Alarcón-Segovia D, Díaz-Jouanen E, Fishbein E. Features of Sjögren's syndrome in primary biliary cirrhosis. Ann Intern Med 1973;79:31-36.

[10] Tsianos EV, Hoofnagle JH, Fox PC, Alspaugh M, Jones EA, Schafer DF, et al. Sjögren's syndrome in patients with primary biliary cirrhosis. Hepatology 1990;11:730-734.

[11] Lindgren S, Manthorpe R, Eriksson S. Autoimmune liver disease in patients with primary Sjögren's syndrome. J Hepatol 1994;20:354-358.

[12] Skopouli FN, Barbatis C, Moutsopoulos HM. Liver involvement in primary Sjögren's syndrome. Br J Rheumatol 1994;33:745-748.

[13] Csepregi A, Szodoray P, Zeher M. Do autoantibodies predict autoimmune liver disease in primary Sjögren's syndrome? Data of 180 patients upon a 5 year follow-up. Scand J Immunol 2002;56:623-629.

[14] Ramos-Casals M, Loustaud-Ratti V, De Vita S, Zeher M, Bosch JA, Toussirot E, et al. SS-HCV Study Group. Sjögren syndrome associated with hepatitis C virus: a multicenter analysis of 137 cases. Medicine 2005;84:81-89.

[15] Abraham S, Begum S, Isenberg D. Hepatic manifestations of autoimmune rheumatic diseases. Ann Rheum Dis 2004;63:123-129.

[16] Ramos-Casals M, Sanchez-Tapias JM, Pares A, Forns X, Brito-Zerón P, Nardi $\mathrm{N}$, et al. Characterization and differentiation of autoimmune versus viral liver 
involvement in patients with Sjögren's syndrome. J Rheumatol 2006;33: 1593-1599.

[17] Liberal R, Grant CR, Mieli-Vergani G, Vergani D. Autoimmune hepatitis: a comprehensive review. J Autoimmun 2013;41:126-139.

[18] Boonstra K, Beuers U, Ponsioen CY. Epidemiology of primary sclerosing cholangitis and primary biliary cirrhosis: a systematic review. J Hepatol 2012;56:1181-1188.

[19] Sanchez Tapias JM, FornsBernhardt X. Hepatitis vírica crónica. In: Medicina Interna, Volume 1, XVII edition, ed. Farreras P, Rozman C. Elsevier, Barcelona, 2012; pp $300-305$.

[20] De Vita S, Sansonno D, Dolcetti R, Ferraccioli G, Carbone A, Cornacchiulo V, et al. Hepatitis $C$ virus infection within a malignant lymphoma lesion in the course of type II mixed cryoglobulinemia. Blood 1995;86:1887-1892.

[21] Koike K, Moriya K, Ishibashi K, Yotsuyanagi H, Shintani $Y$, Fujie H, et al. Sialadenitis histologically resembling Sjögren syndrome in mice transgenic for hepatitis C virus envelope genes. Proc Natl Acad Sci U S A 1997;94:233-236.

[22] Arrieta JJ, Rodríguez-Inigo E, Ortiz-Movilla N, Bartolome J, Pardo M, Manzarbeitia $F$, et al. In situ detection of hepatitis $C$ virus RNA in salivary glands. Am J Pathol 2001;158:259-264.

[23] Toussirot E, Le Huede G, Mougin C, Balblanc JC, Bettinger D, Wendling D. Presence of hepatitis C virus RNA in the salivary glands of patients with Sjögren's syndrome and hepatitis C virus infection. J Rheumatol 2002;29: 2382-2385.

[24] De Vita S, Damato R, De Marchi G, Sacco S, Ferraccioli G. True primary Sjögren's syndrome in a subset of patients with hepatitis $C$ infection: a model linking chronic infection to chronic sialadenitis. Isr Med Assoc J 2002;4: 1101-1105.

[25] Jorgensen C, Legouffe MC, Perney P, Coste J, Tissot B, Segarra C, et al. Sicca syndrome associated with hepatitis C virus infection. Arthritis Rheum 1996; 39:1166-1171.

[26] Ramos-Casals M, García-Carrasco M, Cervera R, Rosas J, Trejo O, de la Red $G$, et al. Hepatitis $C$ virus infection mimicking primary Sjögren syndrome. A clinical and immunologic description of 35 cases. Medicine 2001;80:1-8.

[27] Ramos-Casals M, Stone JH, Cid MC, Bosch X. The cryoglobulinaemias. Lancet 2012;379:348-360.

[28] Smyth CM, McKiernan SM, Hagan R, Pilkington R, O'Regan M, Lawlor E, et al. Chronic hepatitis $C$ infection and sicca syndrome: a clear association with HLA DQB1*02. Eur J Gastroenterol Hepatol 2007;19:493-498.

[29] Kumar A, Ray U, Das S. Human La protein interaction with GCAC near the initiator AUG enhances hepatitis C Virus RNA replication by promoting linkage between $5^{\prime}$ and 3' untranslated regions. J Virol 2013;87:6713-6726.

[30] Brito-Zerón P, Kaveri SV, Bové A, Retamozo S, Akasbi M, Gandía M, et al. Anti-La antibodies as a potential protection for chronic hepatitis $C$ virus infection in patients with Sjögren syndrome: analysis in 663 patients. Rev Clin Esp 2013 (in press).

[31] Nawito Z, Amin A, El-Fadl SA, Abu El Einen K. Sicca complex among Egyptian patients with chronic hepatitis C virus infection. Clin Rheumatol 2011;30: 1299-1304.

[32] Han SH. Extrahepatic manifestations of chronic hepatitis B. Clin Liver Dis 2004; 8:403-418.

[33] Godeau P, Guillevin L, Bletry O, Wechsler B. Periarteritis nodosa associated with hepatitis B virus. 42 cases. Nouv Presse Med 1981;10:1289-1292.

[34] Maya R, Gershwin ME, Shoenfeld Y. Hepatitis B virus (HBV) and autoimmune disease. Clin Rev Allergy Immunol 2008;34:85-102.

[35] Permin H, Aldershvile J, Nielsen JO. Hepatitis B virus infection in patients with rheumatic diseases. Ann Rheum Dis 1982;41:479-482.

[36] Ram M, Anaya JM, Barzilai O, Izhaky D, Porat Katz BS, Blank M, et al. The putative protective role of hepatitis $B$ virus (HBV) infection against autoimmune disorders. Autoimmun Rev 2008;7:621-625.

[37] Bogdanos DP, Smith H, Ma Y, Baum H, Mieli-Vergani G, Vergani D. A study of molecular mimicry and immunological cross-reactivity between hepatitis $B$ surface antigen and myelin mimics. Clin Dev Immunol 2005;12:217-224.

[38] Bach JF. Protective role of infections and vaccinations on autoimmune diseases. J Autoimmun 2001;16:347-353.

[39] Ramos-Casals M, Muñoz S, Zerón PB. Hepatitis C virus and Sjögren's syndrome: trigger or mimic? Rheum Dis Clin North Am 2008;34:869-884.

[40] Aprosin ZG, Serov VV, Lopatkina TN. The hepatitis B virus as a probable etiological factor in Sjögren's disease. Ter Arkh 1993;65:73-78.

[41] Iakimtchouk K, Myrmel H, Jonsson R. Serological screening for hepatitis B and $C$ and human herpes virus 6 in Norwegian patients with primary Sjögren's syndrome. J Rheumatol 1999;26:2065-2066.

[42] Toussirot E, Lohse A, Wendling D, Mougin C. Sjögren's syndrome occurring after hepatitis B vaccination. Arthritis Rheum 2000;43:2139-2140.

[43] Marcos M, Alvarez F, Brito-Zerón P, Bové A, Perez-De-Lis M, Diaz-Lagares C, et al. Chronic hepatitis B virus infection in Sjögren's syndrome. Prevalence and clinical significance in 603 patients. Autoimmun Rev 2009;8:616-620.

[44] Salleras L, Dominguez A, Bruguera M, Plans P, Costa J, Cardenosa N, et al. Declining prevalence of hepatitis B virus infection in Catalonia (Spain) 12 years after the introduction of universal vaccination. Vaccine $2007 ; 25: 8726-$ 8731 .
[45] Chen MH, Hsiao LT, Chen MH, Tsai CY, Huang YH, Chou CT. Clinical significance of chronic hepatitis $B$ virus infection in patients with primary Sjögren's syndrome. Clin Rheumatol 2012;31:309-315.

[46] Chen CH, Yang PM, Huang GT, Lee HS, Sung JL, Sheu JC. Estimation of seroprevalence of hepatitis $B$ virus and hepatitis $C$ virus in Taiwan from a large-scale survey of free hepatic screening participants. J Formos Med Assoc 2007; 106:148-155.

[47] Kang JH, Lin HC. Comorbidities in patients with primary Sjögren's syndrome: a registry-based case-control study. J Rheumatol 2010;37:1188-1194.

[48] Font J, Tàssies D, García-Carrasco M, Ramos-Casals M, Cervera R, Reverter JC, et al. Hepatitis G virus infection in primary Sjögren's syndrome: analysis in a series of 100 patients. Ann Rheum Dis 1998;57:42-44.

[49] Czaja AJ. Immunopathogenesis of autoimmune liver damage. In: Digestive Involvement in Systemic Autoimmune Diseases, ed. Font J, Ramos-Casals M, Rodés J. Elsevier, Amsterdam, 2008; pp 121-140.

[50] Nardi N, Brito-Zerón P, Ramos-Casals M, Aguilo S, Cervera R, Ingelmo M, et al. Circulating auto-antibodies against nuclear and non-nuclear antigens in primary Sjögren's syndrome: prevalence and clinical significance in 335 patients. Clin Rheumatol 2006;25:341-346.

[51] Zurgil N, Bakimer R, Moutsopoulos HM, Tzioufas AG, Youinou P, Isenberg DA, et al. Antimitochondrial (pyruvate dehydrogenase) autoantibodies in autoimmune rheumatic diseases. J Clin Immunol 1992;12:201-209.

[52] Fujikura S, Davis PA, Prindiville T, Leung P, Fox RI, Gershwin ME. Sjögren's syndrome and primary biliary cirrhosis: presence of autoantibodies to purified mitochondrial 2-oxoacid dehydrogenases. J Rheumatol 1990;17: 1453-1457.

[53] Hatzis GS, Fragoulis GE, Karatzaferis A, Delladetsima I, Barbatis C, Moutsopoulos HM. Prevalence and longterm course of primary biliary cirrhosis in primary Sjögren's syndrome. J Rheumatol 2008;35:2012-2016.

[54] Tanaka A, Miyakawa H, Luketic VA, Kaplan M, Storch WB, Gershwin ME. The diagnostic value of anti-mitochondrial antibodies, especially in primary biliary cirrhosis. Cell Mol Biol (Noisy-le-grand) 2002;48:295-299.

[55] Montano-Loza AJ, Crispin-Acuña JC, Remes-Troche JM, Uribe M. Abnormal hepatic biochemistries and clinical liver disease in patients with primary Sjögren syndrome. Ann Hepatol 2007;6:150-155.

[56] Karp JK, Akpek EK, Anders RA. Autoimmune hepatitis in patients with primary Sjögren's syndrome: a series of two-hundred and two patients. Int J Clin Exp Pathol 2010;3:582-586.

[57] Marasini B, Gagetta M, Rossi V, Ferrari P. Rheumatic disorders and primary biliary cirrhosis: an appraisal of 170 Italian patients. Ann Rheum Dis 2001; 60:1046-1049.

[58] Gershwin ME, Selmi C, Worman HJ, Gold EB, Watnik M, Utts J, et al. USA PBC Epidemiology Group. Risk factors and comorbidities in primary biliary cirrhosis: a controlled interview-based study of 1032 patients. Hepatology 2005;42:1194-1202.

[59] Wang L, Zhang FC, Chen H, Zhang X, Xu D, Li YZ, et al. Connective tissue diseases in primary biliary cirrhosis: a population-based cohort study. World J Gastroenterol 2013;19:5131-5137.

[60] Fragoulis GE, Skopouli FN, Selmi C, Gershwin ME. Liver involvement in Primary Sjögren Syndrome. In: Sjögren syndrome. Diagnosis and Therapeutics, ed. M. Ramos-Casals, J. Stone, H. Moutsopoulos. SpringerVerlag, London, 2012; pp 237-246.

[61] Selmi C, Meroni PL, Gershwin ME. Primary biliary cirrhosis and Sjögren's syndrome: autoimmune epithelitis. J Autoimmun 2012;39:34-42.

[62] Uddenfeldt P, Danielsson A, Forssell A, Holm M, Ostberg Y. Features of Sjogren's syndrome in patients with primary biliary cirrhosis. J Intern Med $1991 ; 230: 443-448$.

[63] Kaplan MJ, Ike RW. The liver is a common non-exocrine target in primary Sjogren's syndrome: a retrospective review. BMC Gastroenterol 2002;2:21.

[64] Tishler M, Alosachie I, Barka N, Lin HC, Gershwin ME, Peter JB, et al. Primary Sjogren's syndrome and primary biliary cirrhosis: differences and similarities in the autoantibody profile. Clin Exp Rheumatol 1994;13:497-500.

[65] Prince MI, Chetwynd A, Craig WL, Metcalf JV, James OF. Asymptomatic primary biliary cirrhosis: clinical features, prognosis, and symptom progression in a large population based cohort. Gut 2004;53:865-870.

[66] Selmi C, Mackay IR, Gershwin ME. The autoimmunity of primary biliary cirrhosis and the clonal selection theory. Immunol Cell Biol 2011;89:70-80.

[67] Chiorini JA, Cihakova D, Ouellette CE, Caturegli P. Sjogren syndrome: advances in the pathogenesis from animal models. J Autoimmun 2009;33:190-196

[68] Beswick DR, Klatskin G, Boyer JL. Asymptomatic primary biliary cirrhosis. A progress report on long-term follow-up and natural history. Gastroenterology 1985;89:267-271.

[69] Efe C, Wahlin S, Ozaslan E, Berlot AH, Purnak T, Muratori L, et al. Autoimmune hepatitis/primary biliary cirrhosis overlap syndrome and associated extrahepatic autoimmune diseases. Eur J Gastroenterol Hepatol 2012;24:531-534.

[70] Miller EB, Shichmanter R, Friedman JA, Sokolowski N. Granulomatous hepatitis and Sjögren's syndrome: an association. Semin Arthritis Rheum 2006;36:153-158. 